\title{
Studies of the Turkish form of the Test for Creative Thinking-Drawing Production
}

\author{
Aysenur Yontar Togrol \\ Faculty of Education, Bogazici University, Istanbul, Turkey \\ Email: yontar@boun.edu.tr
}

Received August $16^{\text {th }}, 2012$; revised September $18^{\text {th }}, 2012$; accepted October $2^{\text {nd }}, 2012$

\begin{abstract}
This paper explains the results of multi-year applications of the Test for Creative Thinking-Drawing Production in a Turkish context with Turkish participants. The purpose of the study is to present the results of several empirical studies conducted by different Turkish samples, using the instrument which was developed by Jellen and Urban for measuring the creative thinking potentials of individuals. The number of the subjects of all the studies described here totaled to 1529 . These participants were of various ages and at various levels of ability, and they included primary school students, university students, and adults, as well as 369 gifted students, and 64 subjects with neurological problems. The author introduces the evaluation procedures, discusses the culturally fair characteristics of the test, and makes a case for the utility of the instrument in Turkey with a comparison of existing data in the literature related to the instrument.
\end{abstract}

Keywords: Creativity; Test for Creative Thinking-Drawing Production-TCT-DP; Creative Problem Solving; Divergent Thinking Tests

\section{Introduction}

Creativity is recognized as a valuable human trait for social, technological, economical, and personal reasons. It is important to understand its complexity and its development as a human characteristic, because people express themselves and their imaginative potential best through creativity. For a long time creativity was seen as an extraordinary talent possessed by a few people who became famous for their discoveries or products. On the other hand, authors writing about creativity today tend to accept the premise that all people are creative to some degree in some specific domain-distinguishing between sublime creativity and everyday creativity (Gardner, 1983; Brown, 1989; Baer, 1991, 1996, 1998; Sternberg, 2001; Tan \& Law, 2004; Runco, 2004; Kaufman \& Baer, 2009; Silvia, Nusbaum, Berg, Martin, \& O'Connor, 2009).

Creativity is actually a general term with various definitions, but it usually involves a product or a solution that is both appropriate and novel in the context of a task or problem. Through creativity people generate useful ideas and solutions to challenging problems by combining previously uncombined elements. Creative people see problems where others do not, and produce significant related ideas. They have synthesizing and analyzing abilities; are able to shift from one set of ideas to another, and they can manipulate several interrelated ideas simultaneously. Whatever the profession, a scientist doing a research, a poet writing a poem, an economist proposing the solution to a problem, or a teacher finding a better way to teach, each possesses some of the characteristics of creativity. Of course, motivational and temperamental factors influence whether or not an individual with creative potential actually displays creative behavior. Additionally, historical, cultural, situational, and sociological variables also have an effect on the manifestation of creative behavior. According to Cropley (1999), creativ- ity is facilitated by some social factors and inhibited by others.

According to Guilford (1950), the primary abilities underlying creativity, the following are often discussed: sensitivity to problems (seeing the problems); fluency (producing large numbers of ideas); production of novel ideas (unusual but appropriate); flexibility synthesizing, analyzing, and complexity (the number of interrelated ideas an individual can manipulate at once); and evaluation (selecting good ideas, eliminating bad ideas).

Researchers seem to agree that being creative means being novel and appropriate in context. According to Cropley (2001), there is a common core in the diverse definitions of creativity and this core has three main elements: novelty, effectiveness, and ethicality. Most definitions of creative thinking include the generation of a novel product or idea, or an improvement on a pre-existing product or idea. Appropriateness includes the quailties of fit, utility, and value.

There are several traditions influential in constructing a definition of creativity, which also foster the development of practices and techniques (Sternberg, 2006; Villalba, 2012). Creative thinking is the harmonic interaction of convergent and divergent thinking with a stress on divergent thinking, which is the intellectual ability to think of and produce elaborate original ideas; while convergent thinking is the ability to evaluate, and choose logically the best from a group of ideas. Of these, divergent thinking is no longer considered to be synonymous with creativity but is considered to be an important component of creative thinking. Divergent thinking is also for novel creative products whereas convergent thinking is for their appropriateness. Divergent thinking is finding fifty different ways to use a scissor whereas convergent thinking is finding the most appropriate and relevant uses.

Guilford's (1950) divergent thinking tests are now considered to be the starting point for large-scale efforts to measure 
the construct in a quantitative way. Following Guilford, Torrance's (1966, 1972, 1974) and Wallach and Kogan's, (1965) divergent thinking tests continue the pioneering effort. Because creativity is a complex of characteristics, measurement and evaluation are also complex in nature. Apart from divergent thinking tests, the literature on assessment reports that various other types of instruments have been developed: Attitude and interest inventories, personality inventories, and biographical inventories, ratings by teachers, peers and supervisors, judgments of products, eminence, self-reported creative activities and achievements (Brown, 1981; Cropley, 2000).

The author of the present study prefers to exemplify and focus on one of the measurement instrument developed for assessing the trait. The Test for Creative Thinking-Drawing Production-TCT-DP (Jellen \& Urban, 1987) is one of the instruments developed for measuring the divergent and convergent thinking potentials of individuals. The purpose of this article is to present the results of empirical studies conducted using the TCT-DP and to discuss the characteristics and applicability of the instrument for Turkish participants. This discussion is based on the results of several studies conducted by using different Turkish samples (Togrol, A., Togrol, E., Saracoglu, Tanrıdag, \& Akyatan, 1998; Togrol, 1999; Togrol, 2000; Togrol, A., Togrol, E., \& Can, 2002). In total, the subjects comprised of 1529 participants of belonging to various ages and at various levels of ability, including primary school students, university students, and adults beyond the age of formal schooling (mean age $=28$ ). Also included were 369 gifted students (Togrol, 1999) and 64 subjects with neurological pathologies (Togrol, A., Togrol, E., Saracoglu, Tanrıdag, \& Akyatan, 1998; Togrol, 2000; Togrol, A., Togrol, E., \& Can, 2002). Basic approach of the study is to compare the results of the above mentioned Turkish studies with existing data in the literature and to give an idea related to the relationship of the test scores to some factors like age, gender, level of education, neurological impairment etc.

The TCT-DP was designed by Jellen and Urban as a paperand-pencil instrument that asks the respondents to complete an incomplete drawing-showing six distinct figural fragments placed in a square frame - in any way they wish. According to Urban (2005), the various fragments are geometric and nongeometric, round and straight, singular and compositional, broken and unbroken, either inside or outside a given frame, all irregularly placed and incomplete. When analyzing respondents' drawing products, an evaluator refers to eleven criteria related respectively as;

- Continuations

- Completion

- New elements

- Connections made with a line

- Connections made to produce a theme

- Boundary-breaking that is fragment dependent

- Boundary-breaking that is fragment independent

- Perspective

- Humor and affectivity

- Unconventionality — with following sub criteria-

- Any manipulation of material

- Use of surrealistic, fictional, or abstract elements

- Use of symbols or signs

- Unconventional use of given fragments

- Speed (Jellen \& Urban, 1986, 1987; Urban, 1991, 2005).

These dimensions are derived from a Gestalt psychology theory of creativity (Cropley, 2000). According to Urban (2004)
“.... assessment device may be seen as an attempt to apply a more holistic and gestalt-oriented approach to diagnostics of creativity." A total assigned score indicates the creative value of the drawing. The instrument has two forms, A and B. The test manual includes an extensive description of the evaluation procedure. The 15-minute working time and the broadly applicable age range as well as applicability as an individual or group test are important features of the instrument.

\section{Empirical Studies}

\section{Translation, Reliability and Validity Studies}

Togrol (1999) translated the TCT-DP from English into Turkish, subsequently a back translation study was conducted. Turkish and the English versions of the tests were both administered to university students $(\mathrm{N}=58)$ who were competent in both languages in order to find out sameness of the two forms.

A test-parallel test reliability study of the original test (Urban, 1990), employing a sample of 1100 Hungarian fourth grade students, yielded statistically significant correlation coefficients, a mean of $r=.70$. The correlation coefficients of separate groups varied between $r=.64$ and $r=.77$. Similarly, Togrol (1999) conducted a test-parallel test reliability study of the Turkish version with two groups of sixth and fifth graders $(\mathrm{N}=76)$. $\mathrm{A}$ and $\mathrm{B}$ forms of the test were administered within a period of two months, and the correlation coefficients were $.59(p=.002)$ and $.63(p=.0001)$ respectively, which were taken to be similar to those in the original study.

One of the important issues in using creative thinking assessment techniques is the subjectivity of scoring. The reliability of scoring is an important criterion that researchers must consider when selecting an assessment instrument and designing a research study. So a complex construct such as creativity is assessed using a paper-and-pencil test, inter- and intra-scorer reliability of the instrument becomes crucial. Jellen and Urban conducted several inter-scorer reliability studies with their test and reported that correlation coefficients between the scorings of briefly trained scorers showed a variability between $r=.89$ and $r=1$ (mean $r=.93)$. The mean correlation coefficient for the relationship between assessments of trained scorers was reported as $r=.95$ (Urban, 1990: p. 4). The reported high interscorer reliability coefficients contribute to the usability of the test. In a similar kind of reliability study to obtain evidence of the inter-scorer reliability of the Turkish version, Togrol (1999) selected and scored 39 drawings. The same drawings were also scored independently by an inexperienced scorer who, without any previous training used only the original test manual while scoring. The correlation coefficient between the scores of the experienced and inexperienced scorer was $r=.97(p=.0001)$, a high coefficient parallel to the result of the original study, showing an acceptable level of agreement between scorers.

To obtain evidence of intra-scorer reliability, the Togrol (1999) randomly selected 40 drawings that she had scored previously, and scored them again, several months later. The calculated correlation coefficient between two sets of scores was $\mathrm{r}$ $=.98\left(\chi_{1}=21.05 \chi_{2}=21.45, p=.0001\right)$. In another study similar to the author's by Can, Yasar, and Aral (2010), both the test-retest reliability coefficient (.98) and parallel forms reliability coefficients (.99) were calculated by using a sample of 210 six-year-old Turkish children.

As it was mentioned before, during past years several num- 
bers of creativity tests have been created, although many have not been sufficiently validated (Martinsen, 2011). Gathering evidence related to the validity of an instrument is a difficult task. Comparing results with those derived from a different instrument that measures the same construct is one way to have evidence related to validity, but according to Urban $(1990,2005)$ no other instrument is comparable to the TCT-DP. However, Torrance Test of Creative Thinking (TTCT) is the most widely used (Togrol, 1999; Cropley, 2000; Hu \& Adey, 2002; Almeida, Prieto, Ferrando, Olivera, \& Ferrandiz, 2008; Cropley, 2010; Lau $\&$ Cheung, 2010) and validated (Martinsen, 2011; Kim, 2012) instrument for measuring creative thinking, and as Cropley (1999) reports that, Torrance and Presburg found the TTCT has been used in most of the research studies in the history of creative studies. So Togrol (1999) used the TTCT_-Figural Form A (Torrance, 1972) for the purpose of gathering evidence related to validity.

The TTCT includes both figural and verbal subtests. The figural form A composes of three items - "compose a drawing", "complete a drawing", and "compose a drawing by using repeated parallel lines"-was selected. According to Torrance (1974), items included in the subtests may also be used separately or in combination for measuring the construct, so only the last two questions, which are comparable to the TCT-DP, were used. Both tests were administered to the same group $(\mathrm{N}=$ 70) of fifth and sixth graders with a time interval in between, and the correlation coefficient between the two sets of scores was $\mathrm{r}=.58(p=.0001)$. Also another similar administration, with 32 sixth graders, yielded a correlation coefficient of .56 ( $p$ $=.0002$ ). Results of both studies gave statistically significant positive correlations that can be taken as evidence for the construct validity of the Turkish version of TCT-DP (Togrol, 1999) even though, perhaps because of the different characteristics of the instruments, the correlation coefficient is a modest one. Similarly Blumen-Pardo (2002), conducted a study for gathering evidence related to concurrent validity of TCT-DP by using TTCT. Pearson correlation coefficient between the total scores of both instruments calculated as $.53(p<.001, \mathrm{~N}=49)$ which is very parallel to the Turkish study.

The results of another study by Togrol (2000) may also be accepted as evidence for the validity of the Turkish version of TCT-DP. In this study the researcher investigated the divergent thinking abilities of prospective science $(\mathrm{N}=64)$ and prospective English language teachers $(\mathrm{N}=75)$. The TCT-DP, and two additional instruments, the Objects Test and the Problem Test were used. Both instruments had been developed for the purpose of measuring creative problem-solving abilities. They were administered along with the TCP-DP to a sample of 139 university students, and it was found that the mean scores of the groups were similar in all three of the tests. By using a t-test for independent groups, sub-samples were compared in terms of their divergent thinking abilities, and the comparison showed that there were no statistically significant differences between the mean scores of the groups in terms of the TCT-DP, the Objects Test, and the Problem Test.

How creativity is related to intelligence is not clear enough because of the complexity of each construct (Guilford, 1967; Sternberg \& O'Hara, 1999; Simonton, 2000; Horan, 2007; Furnham \& Bachtiar, 2008; Kaufman, 2009; Kim, 2012), although they clearly interact in the larger context of intellectual ability. The literature seems to say that traditional IQ scores and measures of creativity are only moderately related. "There may even be a threshold of intelligence that is necessary for creative ideation" (Runco, 1999: p. 581). In some studies, relationship between creativity test scores and IQ scores is negligible (Kim, 2005 ) or the relationship is even negatively correlated (Runco, Millar, Acar, \& Cramond, 2010). It appears that intelligence is a necessary but not sufficient condition for creative production. May be as in the paradoxes defined by Cropley (1999) "creativity is not the same as intelligence, but it is also not completely different." Urban (1990) reported a parallel relationship between scores on intelligence tests (German Verbal Creativity Test and Intelligence Structure Test IST-70) and TCT-DP scores. The presence of slightly positive correlations between those scores was reported as evidence for the construct validity of the TCTDP. Urban, in a later study (2005), reported a zero correlation between TCT-DP scores with IQ scores in a high achieving group.

Following the above studies Togrol (1999) conducted a similar correlational study of the Turkish version of the instrument and the Wechsler Intelligence Test for Children Revised (WISC-R) using a sample of 252 fifth grade and 30 sixth grade gifted students. The calculated correlation coefficients of $r_{252}$ $=.20\left(\min =104, \max =152, \chi_{\text {WISC }-\mathrm{R}}=128.1\right)$ and $\mathrm{r}_{30}=.21$ $\left(\min =132, \max =152, \chi_{\text {WISC-R }}=141.1\right)$ reflected a low positive correlation between the constructs. This result is consistent with results in the literature and also the results of Urban's study. Urban $(2004,2005)$ also reported a Polish study conducted by Wolonska and Necka in 1990. The researchers investigated the relationship between Raven's Matrices and the TCT-DP scores of students from several ages: age $7-10, \mathrm{~N}=19, \mathrm{r}=.29$; age $11-18, \mathrm{~N}=410, \mathrm{r}=.21$. These results were very similar to author's 1999 study. According to Getzels (1991) hundreds of similar studies show low correlation coefficients between the two constructs-IQ and creativity - changing between 0 and .7. This accumulation of results mentioned above may be accepted as evidence for construct validity of the test.

Other validity studies of the original instrument were based on the correlation of teacher nominations of students and the students' TCT-DP total scores. It was found that eight out of 14 of these rank correlation coefficients were statistically significant (Urban, 1990: p. 5). A similar study was conducted by Togrol (1999) with a group of primary school students $(\mathrm{N}=132)$ and their teachers. An evaluation form containing questions about the creativity level of their students was administered to three teachers, and it was found that all of the students that the teachers nominated for their creativity had TCT- DP scores above the mean for their class.

\section{Culture Fairness and TCT-DP}

One important criterion used for the evaluation of divergent thinking tests is the originality of a respondent's product or, as the term is used in TCT-DP, its unconventionality. This criterion best reflects the cultural sensitivity of the instrument. In order to identify stereotypical usage of the given figural fragments in the test, each of the drawing productions obtained from administering TCT-DP to $1300(1154+140)$ participants was analyzed according to the whole production and according to each of its six figural fragments (Togrol, 1999). Participants in this particular study included all the samples from all above cited studies. In order to prevent scoring inconsistency, all the drawings were scored again together by the researcher. Transcription of the results identified and classified the stereotypical 
usages of the figural fragments. When the Turkish students' stereotypical usages were compared with those reported in the original test manual, some tendencies were noted. It is an important researcher bias to assume that all cultures are alike and all instruments are culture fair. Analyzing results derived from an instrument within the culture in which it will be used is an important precaution before choosing any instrument. Jellen and Urban (1989 a, 1989 b) conducted a cross-cultural study (N $=569$ ) in eleven different countries. Their aim was to assess the cultural sensitivity and fairness of the instrument. As a result they reported that the instrument is culture fair, culture-sensitive, and gender fair/sensitive. They also clarified that stereotypical thinking is cross-cultural. Based on this, they also added that stereotypical usages of some fragments have some cultural tendencies. The same kind of tendencies in usage of stereotypical usages of fragments were also observed in the Turkish studies conducted by Togrol (1999); for example, completion of one figural element as a television or a car, completion of second one as a human body, which are very typical usages for eastern cultures according to Jellen and Urban (1989). These usages are similar with Turkish participants too. But these tendencies do not change the scoring related to the unconventionality so in that respect instrument is culture fair.

Assessing the instrument in terms of gender fairness was the other focus of interest in the above mentioned cross cultural study. In one of the Turkish study (Togrol, 1999), 230 sixth grade students became a sub-sample for testing the gender differences portrayed in their drawing productions. The group was composed of 113 male and 101 female students. The means of the total scores of girls and boys were compared by the use of a t-test for independent samples. Results of this study showed that there were no significant differences between the mean total scores of two groups $(\mathrm{N}=214, \mathrm{t}=.60, p=.55)$. This result is consistent with results existing in the related literature (Woodman \& Schoenfeld, 1989; Jellen \& Urban, 1990; Baer, 1999; Urban, 2005). Can Yasar and Aral (2010) reported similar findings for a younger age Turkish sample. In their comparative study, using the Mann Whitney U test, there was no significant difference between girls and boys in terms of their total scores from the TCT-DP $(\mathrm{N}=210$, age $=6, \mathrm{z}=-1.35, p>.05)$. Using a t-test for independent samples, Togrol (1999) also investigated differences between the scores of students who were attending schools with different socio-economic compositions. The students $(\mathrm{N}=190)$ were fifth graders from three different schools with students of high, middle, and low socio-economic status. No statistically significant differences were calculated between the creative performances of students from high-middle $(\mathrm{t}=.69, \mathrm{sd}=60.5, p=.49)$, low - middle $(\mathrm{t}=1.95, \mathrm{sd}=69.4, p$ $=.055)$, and high-low groups $(\mathrm{t}=1.13, \mathrm{sd}=72.9, p=.26)$. All of these results provide evidence of the cultural fairness of the instrument.

\section{Neurological Pathologies and Creativity}

Creativity takes place unavoidably inside one's own personal, environmental and social boundaries, which may facilitate or hinder creativity. Various pathologies, diseases, and physical handicaps are also personal variables which may influence an individual's creative behavior. Historically, creatively talented people have often been associated with madness or other forms of disordered behavior (Horan, 2007). Multiple sclerosis (MS) and epilepsy are among the neurological pathologies which may cause cognitive changes in the afflicted individuals.

MS is a progressive chronic disease of the central nervous system. Its symptoms may include those related to cognition, memory, perception, and language as well as motor problems (pareses), spasticity, bowel and bladder problems, sexual problems, visual disturbances, posture and balance problems, and psychological disorders. Researchers (Togrol, A., Togrol, E., Saracoglu, Tanrıdag \& Akyatan, 1998; Togrol, A., Togrol, E., $\&$ Can, 2002) investigated the creative thinking abilities of patient groups by using some medical as well as cognitive instruments, including the TCT-DP. A sample of 34 MS patients and 129 controls were included in the first study (Togrol, A., Togrol, E., Saracoglu, Tanrıdag, \& Akyatan, 1998). All patients were assessed for cognitive dysfunction by the same researcher, using an adapted and standardized form of the Mental Status Examination (Folstein, Folstein, \& Mc Hugh, 1975). Imaging and evoked potential examinations of the MS patients were also conducted. The TCT-DP was used as a screening instrument for testing the creative skills of the sample. Total creativity scores of the groups were not significantly different as compared by t-test for independent samples. Patients with a longer duration of the disease tended to get lower scores. A moderate negative correlation coefficient was found between the variables $(r=$ $-.38, p<.02$ ). As the duration of the disease increased, the total creativity score decreased.

The purpose of the second study (Togrol, A., Togrol, E., \& Can, 2002) was to compare the creative thinking abilities of epilepsy patients with those of normal individuals. 30 epilepsy patients and 36 controls were included in the sample. The mean duration of disease in the epilepsy group was $6.32 \pm 4.9$ years. As in the previous study, TCT-DP was used as a screening instrument for testing the creative thinking potentials of individuals. At the beginning of the study, a detailed neurological examination using a standard cognitive assessment interview technique was used to eliminate gross cognitive pathologies. All patients were assessed for cognitive dysfunction by the same researcher, using the Turkish form of the Mental Status Examination (Yavuz \& Gurtekin, 1997). The total creativity scores of the two groups were compared by using a t-test for independent samples. The mean total score of the control group $(20.83 \pm 7.81)$ was higher than that of the patient group $(16.87$ \pm 9.27 ), and this difference was not statistically significant ( $p$ $=.064$ ). While there were no significant differences between the two groups overall, the researchers did find a possible link between creativity and epilepsy in a subset of seven men with complex partial epilepsy.

\section{Discussion}

Pioneering studies of Guilford (1950), Torrance (1966, 1974), and other scientists collaborating with them lead the widespread usage of instruments developed for measuring creative ability. Nowadays, as a result of ongoing research, there are more approaches to an understanding of creativity as well as different instruments for measuring the trait. For example Hu and Adey (2002) reported that there were more than a hundred creativity tests described and studied in the literature in those days. Today this number may be much higher. Morover studies related to the electronic version compatibility of creative thinking tests have been started (e.g., Lau \& Cheung, 2010). The TCT-DP is one of the paper-pencil instruments, used economically in time and effort for measuring divergent thinking. Its main function is 
as a screening instrument for identifying the creative problem solving potential of individuals. Its broad applicability for different age groups, fairness in terms of gender, socio-economic status and culture are among the strengths of the instrument. The 15-minute sitting time, broadly applicable age range, and minimum training requirements for scoring are additional positive aspects of the instrument.

This article is a review of the results of emprical research studies using the TCT-DP in Turkish samples. Results of the empirical studies were presented in comparison with the results of the similar studies take place in the literature. It is an important bias to assume that different cultures are alike, and research findings from one culture will automatically similar for another culture. Most research studies and theoretical essays (Runco \& Pritzker, 1999; Sternberg, 1999) mainly focus on western-American or/and European-perspectives. So in that respect adapting an instrument to a new culture by clarification its usability is an important task. Coming back to TCT-DP, one of the important characteristics that contribute to its usefulness is its cultural fairness; results obtained so far encourage its applicability for use with Turkish samples. Additionally; its application, scoring and interpretation, simplicity and economic characteristics are its important advantages.

As it is indicated by the results of empirical studies conducted in Turkey, nearly all of them are parallel to the results of the several original studies conducted by Jellen and Urban and existing results conducted by other researchers in the literature. Another group working on the same construct, using Turkish samples, Oral, Kaufman and Agars (2007) examined creativity in three different studies, including the relationship of creativity to motivation, age, gender, and various factors that contribute to creativity. It was reported that, these studies validated research results obtained from other, western samples and it was noted that, for the relationships mentioned above similar findings to other studies were obtained. Similarly several empirical studies conducted by the author using the TCT-DP in Turkey; these studies, in a similar way, revealed results that were consistent with the results of original studies of the instrument.

Creativity is a multi-dimensional construct so its assessment should reflect the same property. Measuring the trait by only using a single paper pencil test will give an idea about respondents' ability framed by that unique instrument and this limitation may lead a weakness in assessment procedure. Obviously each instrument measuring creativity may have different operational definition related to the concept. Finally as a conclusion, TCT-DP offers a culturally fair way to identify and measure creative potential or creative problem solving capabilities of individuals. It may work as a useful tool to identify high creative potentials as well as low or poorly developed ones. Cropley (2000) has stated that "among tests of creative thinking the TCT-DP has much to recommend..." with reasons very similar to the advantages mentioned in this study. So TCT-DP, is an instrument which can be easily used by the researchers and educators as one of the screening instrument.

\section{REFERENCES}

Almeida, L. S., Prieto, L. P., Ferrando, M., Olivera, E., \& Ferrandiz, C. (2008). Torrance test of creative thinking: The question of its construct validity. Thinking Skills and Creativity, 3, 53-58. doi:10.1016/j.tsc.2008.03.003

Baer, J. (1991). Generality of creativity across performance domains.
Creativity Research Journal, 4, 23-39. doi:10.1080/10400419109534371

Baer, J. (1996). The effects of task-specific divergent-thinking training. Creativity Research Journal, 30, 183-187.

Baer, J. (1998). The case for domain specificity of creativity. Creativity Research Journal, 11, 173-177. doi:10.1207/s15326934crj1102 7

Baer, J. (1999). Gender differences. In M. A. Runco, \& S. V. Pritzker (Eds.), Encyclopedia of creativity (pp. 753-758). London: Academic Press.

Blumen-Pardo, S. (2002). Effects of a teacher training workshop on creativity, cognition, and school achievement in gifted and non-gifted second-grade students in Lima, Peru. High Ability Studies, 13, 47-58. doi:10.1080/13598130220132307

Brown, R. T. (1989). Creativity: What are we to measure? In J. A. Glover, R. R. Ronning, \& C. R. Reynolds (Eds.), Handbook of creativity (pp. 3-321). New York: Plenum Press.

Can Yasar, M., \& Aral, N. (2011). The study of the effect of socioeconomic level and parents' educational status on creative thinking skills of six-year-old children. Kuramsal Egitimbilim, 4, 137-145.

Cropley, A. J. (1999). Definitions of creativity. In M. A. Runco, \& S. V. Pritzker (Eds.), Encyclopedia of creativity (pp. 511- 524). London: Academic Press.

Cropley, A. J. (2000). Defining and measuring creativity: Are creativity tests worth using? Roeper Review, 23, 72-79. doi: $10.1080 / 02783190009554069$

Cropley, A. J. (2001). Creativity in education and learning: A guide for teachers and educators. London: Kogan Page.

Folstein, M. F., Folstein, S., \& McHugh, P. R. (1975). Mini mental state: A practical method for grading the cognitive state of patients for the clinician. Journal of Psychiatric Research, 12, 189-198. doi:10.1016/0022-3956(75)90026-6

Funham, A., \& Bachtiar, V. (2008). Personality and intelligence as predictors of creativity. Personality and Individual Differences, 45, 613617. doi:10.1016/j.paid.2008.06.023

Gardner, H. (1983). Frames of mind: The theory of multiple intelligences. New York: Basic Books.

Getzels, J. W. (1991). Creativity and human development. In K. Marjoribanks (Ed.), The foundations of students' learning (pp.155-166). Oxford: Pergamon Press.

Guilford, J. P. (1950). Creativity. American Psychologist, 5, 444-454. doi: $10.1037 / \mathrm{h} 0063487$

Guilford, J. P. (1967). Creativity: Yesterday, today and tomorrow. The Journal of Creative Behavior, 1, 3-14. doi:10.1002/i.2162-6057.1967.tb00002.x

Horan, R. (2007). The relationship between creativity and intelligence: A combined yogic-scientific approach. Creativity Research Journal, 19, 179-202. doi:10.1080/10400410701397230

Hu, W., \& Adey, P. (2002). A scientific creativity test for secondary school students. International Journal of Science Education, 24, 389 403. doi:10.1080/09500690110098912

Jellen, H. G., \& Urban, K. K. (1986). The TCT-DP (Test for creative thinking-drawing production): An instrument that can be applied to most age and ability groups. The Creative Child and Adult Quarterly, 3, 138-151.

Jellen, H. G., \& Urban, K. K. (1987). The TCT-DP: Test for Creative Thinking-Drawing Production manual. Hannover: University of Hannover.

Jellen, H. G., \& Urban, K. K. (1989a). Expanding world-wide awareness of creative potential. Gifted Child Today, 12, 31-33.

Jellen, H. G., \& Urban, K. K. (1989b). Assessing creative potential worldwide: The first cross-cultural application of the test for creative thinking-drawing production (TCT-DP). Gifted Education International, 6, 78-86. doi: $10.1177 / 026142948900600204$

Kim, K. H. (2005). Can only intelligent people be creative? A metaanalysis. The Journal of Secondary Gifted Education, 16, 57-66.

Kim, K. H. (2012). Can we trust creativity tests? A review of the torrance test of creative thinking (TTCT). Creativity Research Journal, 18, 3-14. doi: $10.1207 / \mathrm{s} 15326934 \mathrm{crj} 1801$ 2 2

Kaufman, J. C. (2009). Creativity, intelligence and culture: Connections and possibilities. In P. Meusburger, J. Funke, \& E. Wunder, (Eds.), 
Milieus of creativity-An interdisciplinary approach to spatiality of creativity. New York: Springer.

Kaufman, J. C., \& Baer, J. (2009). Is one dimension enough? A response to Simonton's varieties of (scientific) creativity. Perspectives on Psychological Science, 4, 453-454. doi:10.1111/j.1745-6924.2009.01153.x

Klausen, S. H. (2010). The notion of creativity revisited: A philosophical perspective on creativity research. Creativity Research Journal, 22, 347-360. doi:10.1080/10400419.2010.523390

Lau, S., \& Cheung, P. C. (2010). Creativity assessment: Comparability of the electronic and paper-and-pencil version of the Wallach-Kogan creativity tests. Thinking Skills and Creativity, 5, 101-107.

doi:10.1016/j.tsc.2010.09.004

Martinsen, O. L. (2011). The creative personality: A synthesis and development of the creative person profile. Creativity Research Journal, 23, 185-202. doi:10.1080/10400419.2011.595656

Oral, G., Kaufman, C. J., \& Agars, M. D. (2007). Examining creativity in Turkey: Do western findings apply? High Ability Studies, 18, 235246. doi: $10.1080 / 13598130701709590$

Runco, M. A., \& Pritzker, S. V. (1999). Encyclopedia of creativity. London: Academic Press.

Runco, M. A. (2004). Creativity. Annual Review of Psychology, 55, 657-687. doi:10.1146/annurev.psych.55.090902.141502

Runco, M. A. (2007). Creativity theories and themes: Research, development, and practice. London: Elsevier Inc.

Runco, M. A., Millar, G., Acar, S., \& Cramond, B. (2010). Torrance tests of creative thinking as predictors of personal and public achievement: A fifty-year follow-up. Creativity Research Journal, 22, 361368. doi: $10.1080 / 10400419.2010 .523393$

Silvia, P. J., Nusbaum, E. C., Berg, C., Martin, C., \& O’Connor, A. (2009). Openness to experience, plasticity, and creativity: Exploring lower-order, high-order, and interactive effects. Journal of Research in Personality, 43, 1087-1090. doi:10.1016/j.jrp.2009.04.015

Simonton, D. K. (2000). Creativity: Cognitive, personal, developmental, and social aspects. American Psychologist, 55, 151-158. doi:10.1037/0003-066X.55.1.151

Sternberg, R. J. (1999). Handbook of creativity. New York: Cambridge University Press.

Sternberg, R. J., \& O'Hara L. A. (1999). Encyclopedia of creativity. London: Academic Press.

Sternberg, R. J. (2001). What is the common thread of creativity? Its dialectical relation to intelligence and wisdom. American Psychologist, 56, 360-362. doi:10.1037/0003-066X.56.4.360

Sternberg, R. J. (2006). The nature of creativity. Creativity Research Journal, 18, 87-98. doi:10.1207/s15326934crj1801 10
Tan, A. G., \& Law, L. C. (2004). Creativity for teachers. London: Marshall Cavendish Academic.

Torrance, E. P. (1966). Torrance tests of creative thinking-norms technical manual research edition - verbal tests, forms A and B-figural tests, forms $A$ and B. Princeton: Personnel Pres. Inc.

Torrance, E. P. (1972). Torrance tests of creative thinking - directions manual and scoring guide-figural test, booklet A. Lexington: Personnel Pres. Inc.

Torrance, E. P. (1974). Torrance tests of creative thinking-norms technical manual research edition-verbal tests, forms $A$ and $B$ figural tests, forms A and B . Princeton: Personnel Pres. Inc.

Togrol, A., Togrol, E., Saracoglu, M., Tanrıdag, O., \& Akyatan, N. (1998). Creativity in multiple sclerosis. International Journal of Psychophysiology, 30, 139. doi:10.1016/S0167-8760(98)90359-2

Togrol, A. (1999). Turkish form of the test for creative thinking. Egitim ve Bilim Dergisi, 23, 45-51.

Togrol, A. (2000). Prospective teachers' divergent thinking abilities. Fourth International Conference on Creative Thinking, Malta, 24-25 July 2000.

Togrol, E., Togrol, A., \& Can, S. (2002). Creative thinking in epilepsy. 12th Meeting of the European Neurological Society, Berlin, 22-26 June 2002.

Urban, K. (1990). The test for creative thinking-drawing production (TCT-DP). Hannover: University of Hannover.

Urban, K. K. (1991). On the development of creativity in children. Creativity Research Journal, 4, 177-179. doi:10.1080/10400419109534384

Urban, K. K. (2004). Assessing creativity: The test for creative thinking-drawing production (TCT-DP) - The concept, application, evaluation, and international studies. Psychology Science, 46, 387-397.

Urban, K. K. (2005). Assessing creativity: The test for creative thinking-drawing production (TCT-DP). International Education Journal, 6, 272-280.

Villalba, E. (2012). Searching for holy grail of measuring creativity. Creativity Research Journal, 24, 1-2. doi:10.1080/10400419.2012.649235

Yavuz, N., \& Gurtekin, Y. (1997). Unutkanlık ve kısa mental durum degerlendirme testi (KMDDT). GATA Bulteni, 39, 251-255.

Wallach, M. A., \& Kogan, N. (1965). Modes of thinking in young children. New York: Holt, Rinehart, \& Winston.

Woodman, R. W., \& Schoenfeld, L. F. (1989). Individual differences in creativity: An interactionist perspective. In J. A. Glover, R. R. Ronning, \& C. R. Reynolds (Eds.), Handbook of creativity (pp. 77-91). New York: Plenum Press. 